\title{
HIF2a contributes to antiestrogen resistance via positive bilateral crosstalk with EGFR in breast cancer cells
}

\author{
Muhammad Wasi Alam¹, Camilla Ulrika Persson ${ }^{1}$, Susann Reinbothe ${ }^{1}$, Julhash \\ U. Kazi ${ }^{1}$, Lars Rönnstrand ${ }^{1}$, Caroline Wigerup ${ }^{1}$, Henrik Jorn Ditzel ${ }^{2}$, Anne E. \\ Lykkesfeldt ${ }^{3}$, Sven PåhIman ${ }^{1}$, Annika Jögi ${ }^{1}$ \\ ${ }^{1}$ Department of Laboratory Medicine, Translational Cancer Research, Lund University Cancer Center at Medicon Village, Lund \\ University, Sweden \\ ${ }^{2}$ Department of Cancer and Inflammation Research, University of Southern Denmark, and Department of Oncology, Odense \\ University Hospital, Odense, Denmark \\ ${ }^{3}$ Breast Cancer Group, Cell Death and Metabolism, Danish Cancer Society Research Center, Copenhagen, Denmark
}

Correspondence to: Annika Jögi, e-mail: Annika.jogi@med.lu.se

Keywords: breast cancer, antiestrogen, endocrine therapy, hypoxia, hypoxia inducible factor

Received: July 07, 2015

Accepted: January 22, 2016

Published: February 03, 2016

\section{ABSTRACT}

The majority of breast cancers express estrogen receptor a (ERa), and most patients with ERa-positive breast cancer benefit from antiestrogen therapy. The ERamodulator tamoxifen and ERa-downregulator fulvestrant are commonly employed antiestrogens. Antiestrogen resistance remains a clinical challenge, with few effective treatments available for patients with antiestrogen-resistant breast cancer. Hypoxia, which is intrinsic to most tumors, promotes aggressive disease, with the hypoxia-inducible transcription factors HIF1 and HIF2 regulating cellular responses to hypoxia. Here, we show that the ERa-expressing breast cancer cells MCF-7, CAMA-1, and T47D are less sensitive to antiestrogens when hypoxic. Furthermore, protein and mRNA levels of HIF2a/HIF2A were increased in a panel of antiestrogenresistant cells, and antiestrogen-exposure further increased HIF2a expression. Ectopic expression of HIF2a in MCF-7 cells significantly decreased sensitivity to antiestrogens, further implicating HIF2a in antiestrogen resistance. EGFR is known to contribute to antiestrogen resistance: we further show that HIF2a drives hypoxic induction of EGFR and that EGFR induces HIF2a expression. Downregulation or inhibition of EGFR led to decreased HIF2a levels. This positive and bilateral HIF2EGFR regulatory crosstalk promotes antiestrogen resistance and, where intrinsic hypoxic resistance exists, therapy itself may exacerbate the problem. Finally, inhibition of HIFs by FM19G11 restores antiestrogen sensitivity in resistant cells. Targeting HIF2 may be useful for counteracting antiestrogen resistance in the clinic.

\section{INTRODUCTION}

Selective estrogen receptor modulators (SERMs) like tamoxifen, and selective estrogen receptor down-regulators (SERDs) like fulvestrant, are widely used to treat estrogen receptor $\alpha(E R \alpha)$-positive breast cancer. These drugs reduce tumor growth and metastasis by counteracting ER $\alpha$-induced proliferation [1]. Antiestrogen resistance frequently occurs, particularly in patients with highstage disease [2], posing a prominent clinical difficulty. Resistance can be intrinsic (de novo resistance), but more commonly it arises during treatment (acquired resistance).
ER $\alpha$ (encoded by ESR1 or NR3A1) binds estrogen (the most potent estrogen is estradiol, E2) in a hydrophobic pocket, inducing receptor conformational changes, dimer formation and transcriptional regulation of genes with ER $\alpha$ binding-sites in their promoters. Tamoxifen and its active metabolite 4-hydroxytamoxifen, competitively binds to the same hydrophobic pocket in ER $\alpha$ as E2 does, but induces a different conformational change to modulate, although not completely abolish, ER $\alpha$ signaling [3]. SERDs also bind to this hydrophobic pocket to induce conformational changes that abolish ER $\alpha$ signaling and cause proteasomal degradation of ER $\alpha$ [4]. 
Most solid tumors harbor poorly oxygenated, hypoxic, areas due to insufficient circulation. Hypoxia results in the stabilization and activation of the hypoxiainducible transcription factor alpha-subunits HIF $1 \alpha$ and HIF $2 \alpha[5,6]$. To induce transcription, the alpha-subunits dimerize with HIF $\beta / A R N T$ and translocate to the nucleus, where $H I F \alpha / H I F \beta$-complexes bind hypoxia-responsive element (HRE) sites in the promoters of genes including vascular endothelial growth factor $(V E G F)$ and $E P O$. Stabilization of HIF $1 \alpha$ and HIF $2 \alpha$ contributes to hypoxic cell survival and neovascularization [7]. It is well known that tumor hypoxia is associated with poor prognosis and therapeutic resistance [8]. Our laboratory previously reported that high HIF2 $\alpha$ protein levels are associated with distant metastases and poor outcomes in breast cancer patients [9].

Activation of alternative growth and survival signaling pathways, e.g. human epidermal growth factor receptor (HER1 or EGFR) and HER2, has been described in antiestrogen therapy-resistant breast cancer $[10,11]$. HIF $1 \alpha$ and HIF $2 \alpha$ are implicated in therapeutic resistance in breast cancer $[12,13]$, and HIF2 $\alpha$ influences EGFR translation $[14,15]$ at hypoxia. To test if hypoxia per se can induce antiestrogen resistance and to establish the mechanisms for the potential hypoxia-induced resistance, we investigated how hypoxia and HIFs affect sensitivity to tamoxifen and fulvestrant. We observed that hypoxic conditions increased the proportion of viable cells after antiestrogen treatment. HIF $2 \alpha$ expression was increased in antiestrogen-resistant cells, and co-treatment with the HIF-inhibitor FM19G11 restored their antiestrogen sensitivity. Ectopic expression of HIF2 $\alpha$ significantly increased the viability of MCF-7 cells after exposure to tamoxifen or fulvestrant, further strengthening the link between HIF2 $\alpha$ and antiestrogen resistance. EGFR expression was increased in antiestrogen-resistant cells (as previously reported for fulvestrant-resistant cells [16]) and further induced by hypoxia. Silencing HIF $2 \alpha$ significantly lowered EGFR expression, whereas HIF2 $\alpha$ overexpression induced EGFR. Finally, EGFR induced HIF2 $\alpha$ expression, suggesting that these two proteins form a positive regulatory-loop that promotes antiestrogen resistance.

\section{RESULTS}

\section{Effects of hypoxia on antiestrogen treatment in ERo-positive breast cancer cells}

We hypothesized that hypoxia would reduce the effect of antiestrogen treatment, since ER $\alpha$ is downregulated in response to hypoxia (Figure 1A). Tamoxifen treatment resulted in increased protein expression of $E R \alpha$, whereas fulvestrant treatment led to decreased protein expression of ER $\alpha$ (Figure 1A), as anticipated [4], and the hypoxic ER $\alpha$-downregulating effect persisted in antiestrogen-treated cells (Figure 1A).
We next examined if antiestrogen sensitivity was affected by hypoxia in ER $\alpha$-positive cell lines: MCF-7, CAMA-1, and T47D. All three cell lines were less sensitive to antiestrogens under hypoxic conditions (Figure 1B). However, the transcriptional activity of $\mathrm{ER} \alpha$ was not affected by hypoxia as assessed by an ER $\alpha$ luciferase reporter assay (Figure 1C), suggesting that ER $\alpha$ itself is unlikely to be responsible for the decreased antiestrogen effect during hypoxia.

Since HIFs are important mediators of hypoxic adaptation, HIF $1 \alpha$ and HIF $2 \alpha$ protein levels were assessed in MCF-7 cells after $72 \mathrm{~h}$ (a time-point at which neither tamoxifen nor fulvestrant had caused significant differences in cell density) in the absence or presence of antiestrogen showing similar accumulation of both factors under hypoxic conditions (Figure 1D). Dipyridyl (DIP) treatment leads to HIF $\alpha$ protein accumulation by inhibiting VHL-dependent proteasomal degradation and was used as a positive control for HIF $1 \alpha$ and HIF $2 \alpha$ protein detection (Figure 1D). The kinetics of HIF $1 \alpha$ and HIF $2 \alpha$ accumulation in response to hypoxia varied, with HIF $1 \alpha$ expression increasing prior to $6 \mathrm{~h}$ and declining at $72 \mathrm{~h}$ (Figure 1E). In contrast, HIF2 $\alpha$ protein expression continued to increase even at $72 \mathrm{~h}$ of hypoxia (Figure 1E). We did not detect significant differences in cell density between control and drug-exposed cells as early as at $72 \mathrm{~h}$ of exposure (data not shown), which may indicate that any HIF-dependent influence on sensitivity is likely to be via the action of HIF $2 \alpha$ as this is the dominating isoform at later time-points.

To further analyze the nature of hypoxia-induced antiestrogen resistance, we utilized a panel of antiestrogenresistant cell lines that were generated from MCF-7 cells surviving longterm treatment with growth arresting concentration of tamoxifen (TAMR1) or fulvestrant (FUR1 and FUR2) [17-19]. As anticipated, an increased percentage of drug-resistant cells survived exposure to antiestrogens compared to parental MCF-7 cells (Figure 1F and Supplementary Figure S1). Notably, resistance was further increased under hypoxic conditions (Figure $1 \mathrm{~F}$ and Supplementary Figure S1).

\section{Breast cancer cells with acquired antiestrogen resistance have increased protein levels of HIF2 $\alpha$, but not HIF1 $\alpha$}

We next investigated HIF protein levels in the antiestrogen-resistant cell lines TAMR1, FUR1, and FUR2. All three resistant cell lines expressed HIF1 $\alpha$ protein at levels comparable to, or lower than, the parental cell line under normoxic (where HIF $1 \alpha$ protein is hardly detectable) and hypoxic conditions at $72 \mathrm{~h}$ (Figure 2A-2C, upper panels). HIF2 $\alpha$ was detected under normoxic conditions in all three antiestrogen-resistant cell lines, with expression further increasing with hypoxia; however, in parental MCF-7 cells, HIF2 $\alpha$ expression was robust 
mainly under hypoxic conditions (Figure 2A-2C). HIF $2 \alpha$ signals were quantified and normalized to SDHA levels (Figure 2A-2C, graphs): both tamoxifen- (TAMR1) and fulvestrant-resistant (FUR1 and FUR2) cells expressed significantly higher levels of HIF $2 \alpha$ protein compared

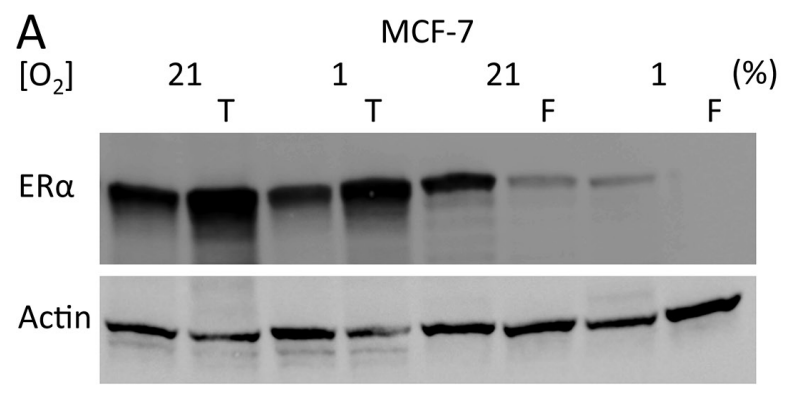

C

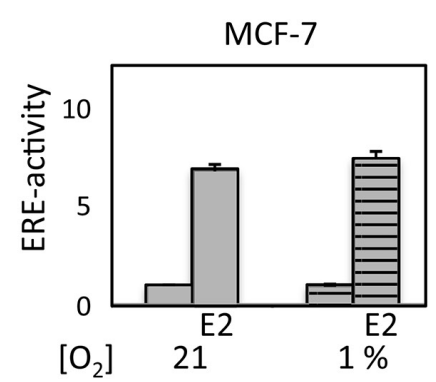

$\mathrm{D}$

$\left[\mathrm{O}_{2}\right]$

HIF1 $\alpha$

SDHA

HIF2a

SDHA

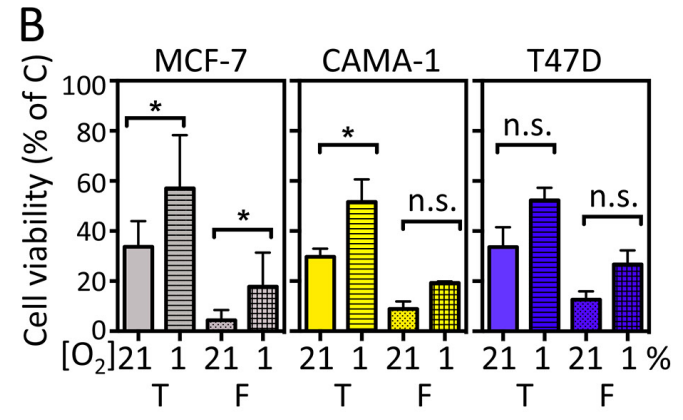

to parental cells under normoxic and hypoxic conditions (Figure 2A-2C). Furthermore, HIF $2 \alpha$ protein levels increased significantly with drug-exposure in hypoxic antiestrogen-resistant cells, a trend also visible at normoxia (Figure 2A-2C). ER $\alpha$ levels were lower in TAMR1 cells
E

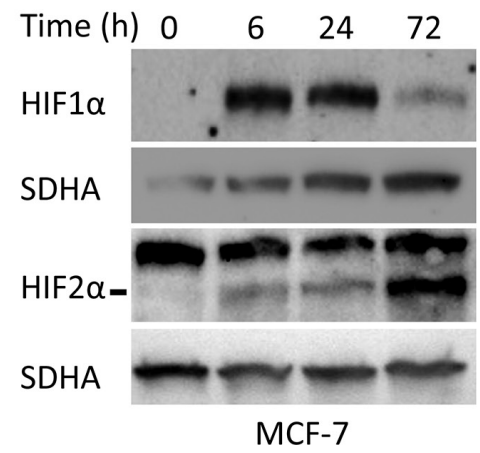

$\mathrm{F}$

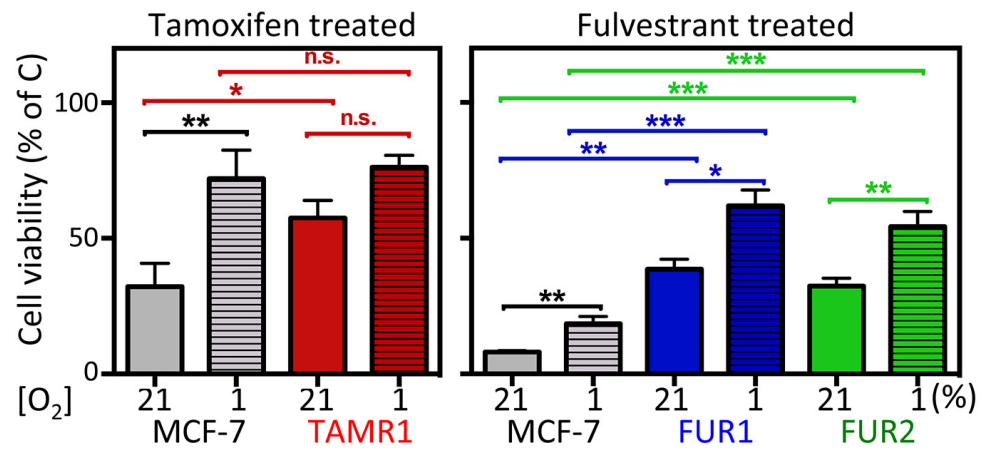

Figure 1: Effects of hypoxia and antiestrogen treatment in estrogen receptor-positive breast cancer cells. (A) Treatment of MCF-7 cells with $0.5 \mu \mathrm{M}$ tamoxifen for $72 \mathrm{~h}$ at normoxic and hypoxic conditions results in increased protein levels of ER $\alpha$. Fulvestrant has the opposite effect. Actin was used as a loading control. (B) Cell viability displayed as percentage of untreated control cells (C) for three ER $\alpha$-positive cell lines: MCF-7, CAMA-1, and T47D. The cells were counted after exposure to antiestrogens under hypoxic (1\%) or control $(21 \%)$ conditions for six days. Three independent experiments in triplicate were performed for each cell line. The differences in percentages of surviving cells were significant where indicated $\left(^{*}\right)$. In the other settings (n.s.), the differences were statistically significant in two of the three experiments. Student's $t$-test, significance $* p<0.05$. (C) Transcriptional activity of ER $\alpha$ in MCF-7 cells analyzed by an EREluciferase assay under control (21\%) and hypoxic (1\%) conditions with and without addition of $17-\beta$-estradiol (E2) for $24 \mathrm{~h}$ to the culture medium. (D) western blot analyses for HIF1 $\alpha$ and HIF2 $\alpha$ in MCF-7 cells cultured under the indicated oxygen conditions for $72 \mathrm{~h}$. Dipyridyl (DIP) treatment leads to HIF $\alpha$-subunit accumulation and was used to generate positive controls for western blots since the HIF $2 \alpha$ antibody also detects a non-specific product. DIP indicates exposure for $24 \mathrm{~h}[100 \mu \mathrm{M}]$; less amount of sample was loaded to avoid overflow into adjacent wells. SDHA was used as a loading control. The HIF2 $\alpha$ protein is indicated with a line. (E) Western blot for HIF $1 \alpha$ and HIF2 $\alpha$ at the indicated time points of exposure to hypoxic conditions (1\% oxygen). SDHA was used as a loading control. The HIF2 $\alpha$ protein is indicated with a line. (F) Cell viability (\% of non-drug-treated control cells) after six days of tamoxifen $[0.5 \mu \mathrm{M}]$ or fulvestrant $[0.5 \mu \mathrm{M}]$ exposure to tamoxifen- (TAMR1) and fulvestrant- (FUR1 and 2) resistant MCF-7 cells at $21 \%$ oxygen and 1\% oxygen, respectively. Data presented are the mean from three independent experiments in triplicate. Statistical analysis with Student's $t$-test, ${ }^{*} p<0.05, * * p<0.01, * * * p<0.001$. 
than in MCF-7 parental cells, increased with tamoxifen treatment, and decreased at hypoxia (Figure 2D). FUR1 also expressed less ER $\alpha$ than parental MCF-7 cells and, at hypoxia and in the presence of fulvestrant, ER $\alpha$ levels further decreased and was hardly detectable (Figure 2D). FUR2 cells expressed ER $\alpha$ at levels comparable to MCF-7 cells under control conditions, but in fulvestrant- or hypoxia-treated cells ER $\alpha$ levels were consistently lower (Figure 2D). Since low protein levels of ER $\alpha$ (hypoxia and fulvestrant treatment) and impaired function of ER $\alpha$ (tamoxifen) were associated with high protein levels of HIF $2 \alpha$, we examined the effect of siRNA-mediated knockdown of $\mathrm{ER} \alpha$ in these cells. Following reduction of ER $\alpha$ increased protein levels of HIF $2 \alpha$ were observed two days after transfection (Supplementary Figure S2).

Treatment of patients with high doses of estrogen has been suggested as a strategy against progressed hormone-responsive breast cancer $[20,21]$. Incubation with high concentrations of $17 \beta$-estradiol $(10 \mu \mathrm{M})$ for $72 \mathrm{~h}$ (i.e. before decreased cell numbers in treated cultures are seen at 6-7 days) lead to increased HIF2 $\alpha$ protein levels in both MCF-7 and antiestrogen-resistant cell lines (Supplementary Figure S2). In the resistant cells, but not in MCF-7, a slight increase in EGFR levels was also seen, which may reflect a stress response, especially in the resistant cell lines, since estrogen induces apoptosis in breast cancer cells adapted to long-term estrogen deprivation [22].

\section{HIF2A mRNA levels are elevated in antiestrogen resistant cells}

It is thought that both HIF $1 \alpha$ and HIF $2 \alpha$ are primarily regulated by protein stabilization in response to low oxygen levels; however, we observed that the protein levels of HIF $2 \alpha$ in the developing sympathetic nervous system and in hypoxic neuroblastoma are at least partially regulated transcriptionally [23]. Analysis of HIF 2A (EPAS1) mRNA expression after $72 \mathrm{~h}$ of exposure to tamoxifen and fulvestrant revealed that $H I F 2 A$ mRNA expression was higher in TAMR1, FUR1, and FUR2 cells than in parental MCF-7 cells under normoxic and hypoxic conditions (Figure 3A-3C). Interestingly, HIF $2 A$ mRNA expression was consistently greater in hypoxic cells than corresponding normoxic cells (Figure 3D). We conclude that increased HIF $2 \alpha$ protein expression in breast cancer cells appears to be regulated transcriptionally in response to hypoxia, at least in part. Analysis of published cDNA microarray data [24] revealed 12-fold greater $H I F 2 A$ mRNA expression in four tamoxifen-resistant cell lines (including TAMR1) than the parental cell line $(p<0.001)$, and 26-fold greater mRNA expression in seven fulvestrant-resistant cell lines including FUR1 and FUR2 $(p<0.001)$. In contrast, the HIF1A mRNA levels did not vary significantly between the antiestrogen-resistant cells and the parental MCF-7 cells or with exposure to drugs or hypoxic conditions (data not shown), consistent with a post-transcriptional hypoxic induction of HIF $1 \alpha$.

\section{HIF inhibition restores sensitivity to antiestrogens in resistant cells}

We next sought to inhibit HIF2 $\alpha$ activity in antiestrogen-resistant cells to test the hypothesis that this would restore antiestrogen sensitivity. As shown above (Figure 1E), HIF2 $\alpha$ appears to play a greater role than HIF $1 \alpha$ in processes occurring at or after $72 \mathrm{~h}$ of hypoxia. Since knock-down experiments using siHIF2A and shHIF2A were unsuccessful over longer periods of antiestrogen exposure (six to nine days), we exploited a commercially available and well-tolerated HIF inhibitor, FM19G11 [25], which inhibits both HIF1 and HIF2 activities and decreases expression of downstream target genes [25].

To ensure efficacy of the HIF-inhibitor, FM19G11, in these cell lines, HRE-luciferase reporter assays were performed to measure HIF-induced transcription at normoxia and hypoxia of all cell lines in the presence and absence of the HIF-inhibitor (Figure 4A and 4B). By inhibiting VHL-dependent proteasomal degradation, DIP treatment accumulates HIF $\alpha$ and activates HIF transcriptional activity, reported via HRE-luciferase activity. Combined exposure to hypoxia further increased HIF transcriptional activity (Figure 4A), which might be due to loss of inhibitory hydroxylation of the HIF $\alpha$ $\mathrm{N}$-terminal transactivating domain by factor inhibiting HIF (FIH-1) when oxygen is available. One $\mu \mathrm{M}$ of FM19G11 led to a several-fold and statistically significant decrease in HRE reporter activity compared to DIP alone in all tested cell lines at $72 \mathrm{~h}$ (Figure 4A and $4 \mathrm{~B}$ ). There was a tendency toward decreased HIF $2 \alpha$ protein expression in the presence of the HIF inhibitor, (Supplementary Figure S3A).

We next tested the effect of FM19G11 on cell survival in the presence of antiestrogens. In antiestrogenresistant cells, under normoxic conditions (when HIF $2 \alpha$ levels are high and HIF1 $\alpha$ levels are low), FM19G11 significantly increased sensitivity to tamoxifen in TAMR1 cells and sensitivity to fulvestrant in FUR1 and FUR2 cells (Figure 4C). A slight increase in sensitivity to tamoxifen and fulvestrant was also observed for MCF-7 parental cells, albeit from very low to even lower viability levels (Figure 4C and Supplementary Figure S4). Increased concentrations of FM19G11 increased the effect of fulvestrant as shown in FUR2 (Figure 4D), the cell line with highest expression level of HIF $2 \alpha$.

\section{Overexpression of HIF $2 \alpha$ increased cell viability in combination with antiestrogen treatment}

To further examine the link between HIF2 $\alpha$ expression and antiestrogen-resistance, an oxygen-stable 
variant of HIF2 $\alpha$ [26] was expressed in parental MCF-7 cells by viral transduction. These cells (MCF-7 H2) expressed high levels of HIF $2 \alpha$ protein at normoxia, which further increased with hypoxia (Figure 5A). In agreement, these cells also showed high HRE-luciferase activity, which further increased with hypoxia (Figure 5B). ARNT/ HIF1 $\beta$ was essentially uniformly expressed between subclones and conditions (Supplementary Figure S5). Next, we exposed HIF2 $\alpha$-overexpressing MCF-7 cells to antiestrogens and analyzed the percentage of surviving cells after six days at normoxia and hypoxia. The ectopically HIF2 $\alpha$-overexpressing MCF-7 cells were less sensitive to tamoxifen and fulvestrant than parental and control transduced MCF-7 cells (Figure 5C). At hypoxia, the treatment resistance inferred by HIF $2 \alpha$ overexpression was even more pronounced, approaching resistance levels seen in TAMR1 and FUR2 cells (Figure 5C). We then co-exposed the virus-transduced cells to antiestrogens and FM19G11 HIF-inhibitor $(2 \mu \mathrm{M})$ confirming that the HIF $2 \alpha$-induced resistance was counteracted by HIFinhibition (Figure 5D). In conclusion, overexpression of HIF $2 \alpha$ increased the proportion of surviving cells in the presence of antiestrogens compared to control cells, and drug-sensitivity was rescued by HIF-inhibition.
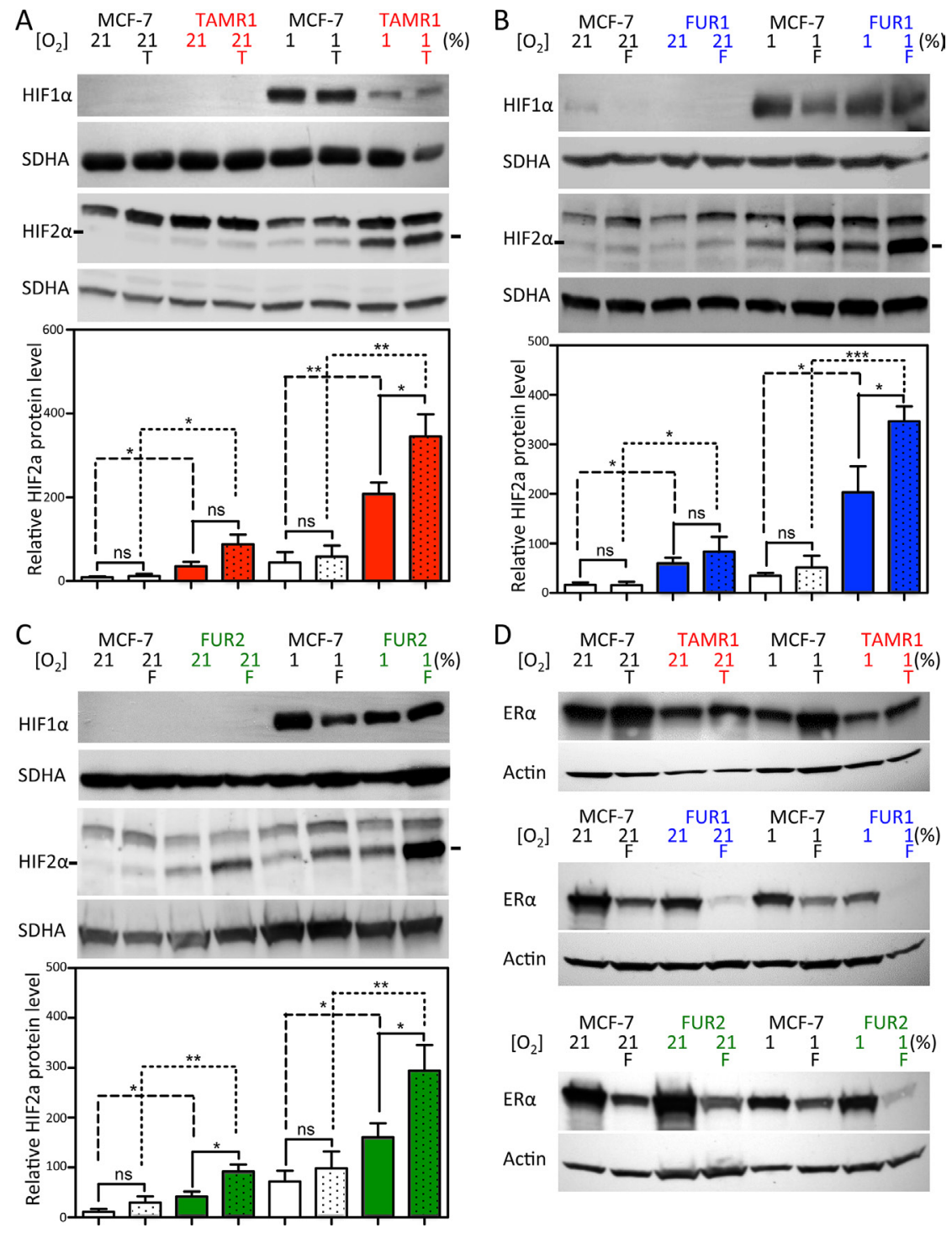

Figure 2: Effect of hypoxia and antiestrogen treatment on HIF1 $\alpha$ and HIF2 $\alpha$ in MCF-7 and antiestrogen-resistant breast cancer cells. (A-C) MCF-7-derived cell lines with acquired resistance to tamoxifen (TAMR1) and fulvestrant (FUR1 and FUR2) were exposed to tamoxifen $[0.5 \mu \mathrm{M}](\mathrm{T})$ or fulvestrant $[0.5 \mu \mathrm{M}](\mathrm{F})$ under normoxic and hypoxic conditions for $72 \mathrm{~h}$ and analyzed for HIF $1 \alpha$ and HIF $2 \alpha$ protein expression by western blotting. SDHA was used as a loading control. The charts show quantification of the HIF $2 \alpha$ levels normalized to SDHA in 3-4 independent experiments. Statistical analyses with one-tailed Student's $t$-test, ${ }^{*} p<0.05$, ${ }^{* *} p<0.01$, $* * * p<0.001$. (D) Western blot analyses of ER $\alpha$ protein levels in whole cell lysates of TAMR1, FUR1, and FUR2 cells compared to MCF-7 parental cells. Cells were harvested $72 \mathrm{~h}$ after addition of tamoxifen $[0.5 \mu \mathrm{M}](\mathrm{T})$ or fulvestrant $[0.5 \mu \mathrm{M}](\mathrm{F})$ to the growth medium under hypoxic (1\%) or normoxic (21\%) conditions. Actin was used as a loading control. 

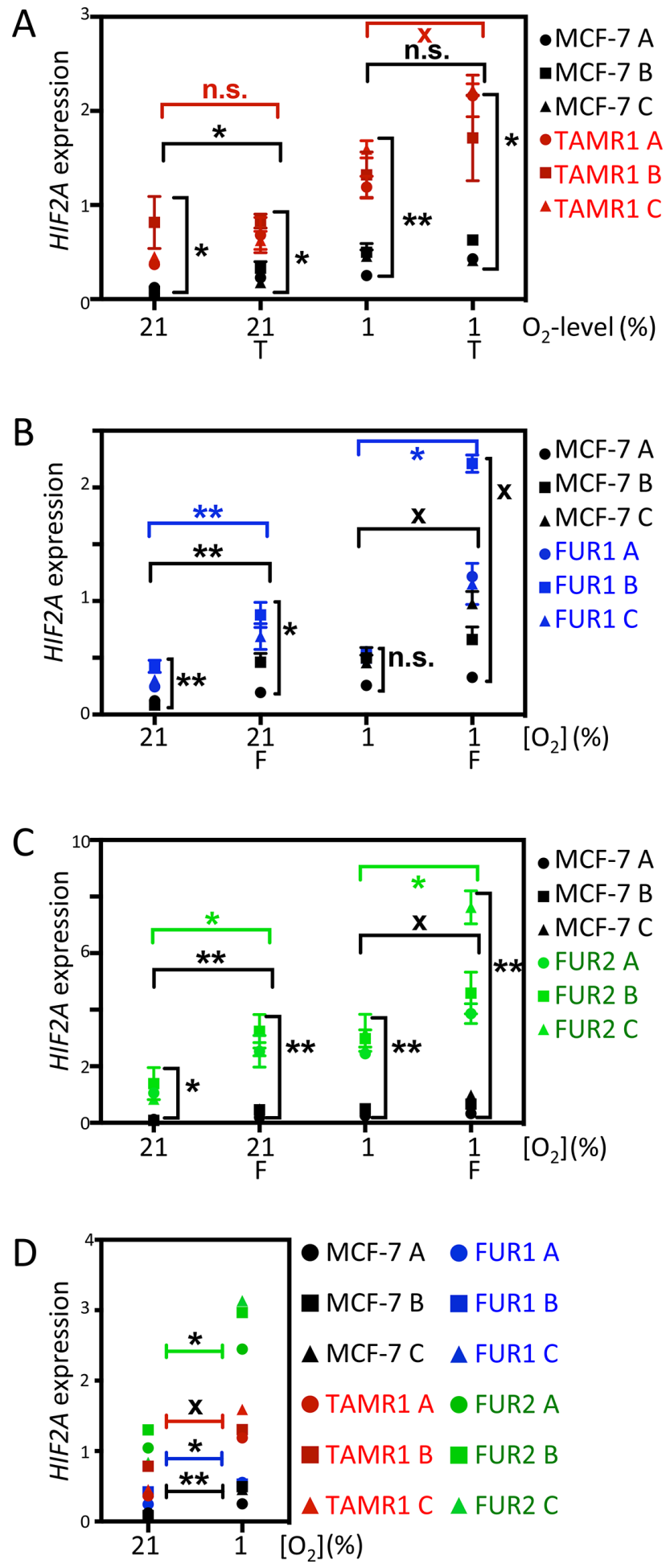

Figure 3: Effect of hypoxia and antiestrogen on HIF2 $\alpha$ mRNA expression in MCF-7 and antiestrogen resistant breast cancer cells. (A-C) Comparison of relative HIF2 $\alpha$ mRNA levels in tamoxifen- (TAMR1) and fulvestrant- (FUR1 and FUR2) resistant cells exposed to tamoxifen $[0.5 \mu \mathrm{M}](\mathrm{T})$ or fulvestrant $[0.5 \mu \mathrm{M}](\mathrm{F})$ under normoxic and hypoxic conditions for $72 \mathrm{~h}$. HIF $2 \alpha$ mRNA levels were measured by qRT-PCR and normalized to the geometric mean of the expression of three reference genes: SDHA, UBC, and YWHAZ. A, B, and C in the chart denote three independent experiments. Statistical analyses with Student's $t$-test, ${ }^{*} p<0.05,{ }^{* *} p<0.01$, $* * *<0.001$. X acknowledges that the difference between groups was significant $*$ in two out of three independent experiments. (D) Direct comparison of HIF2 $\alpha$ mRNA levels in the different sub-cell lines at $21 \%$ and $1 \%$ oxygen. A, B, and C in the diagram denote three independent experiments. Statistical analyses with Student's $t$-test, ${ }^{*} p<0.05,{ }^{* *} p<0.01,{ }^{* * *} p<0.001$. X denotes that the difference between the groups was significant * in two out of three independent experiments. HIF2 $\alpha$ mRNA as measured in triplicate by qRT-PCR and normalized to the geometric mean of the expression of three reference genes: SDHA, UBC, and YWHAZ. 


\section{HIF $2 \alpha$ and EGFR protein levels are interdependent in antiestrogen-resistant cells}

Since the fulvestrant-resistant cells were reported to express high levels of EGFR that contributes to their resistant phenotype [16], we investigated the effect of hypoxia on EGFR levels in antiestrogen-resistant and parental cells. EGFR expression was higher and increased in response to hypoxia in TAMR1, FUR1 and
FUR2 cells (Figure 6A). Since HIF2 $\alpha$ is reported to induce EGFR protein levels under hypoxic conditions in renal epithelial cells [14], we tested the effect of HIF $2 \alpha$ downregulation by siRNA on EGFR protein levels in antiestrogen-resistant breast cancer cells. HIF $2 \alpha$ silencing resulted in significantly lower levels of EGFR in both FUR1 and FUR2 cells at hypoxia (Figure 6B and 6C). Also in TAMR1 cells siHIF2 $\alpha$ led to decreased EGFR expression, though initial levels were lower in these cells
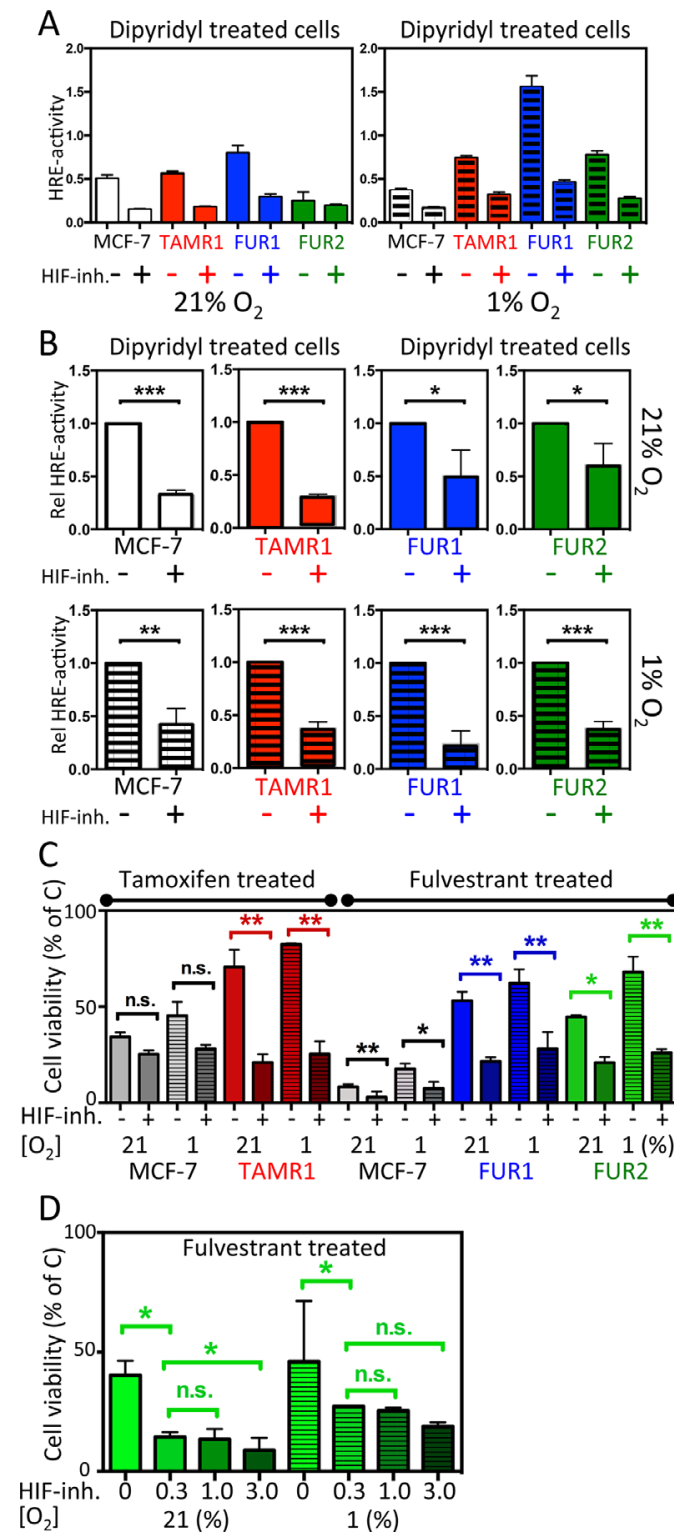

Figure 4: Effect of the HIF-inhibitor FM19G11 on HIF-transcriptional activity and response to antiestrogen treatment in MCF-7 and antiestrogen resistant breast cancer cells. (A-B) MCF-7, TAMR1, FUR1, and FUR2 cells transiently transfected with the HRE-luciferase reporter and a separate plasmid encoding Renilla luciferase were grown under normoxic or hypoxic conditions for $72 \mathrm{~h}$ and, over the final $24 \mathrm{~h}$, all samples were exposed to dipyridyl [100 $\mu \mathrm{M}]$ with or without addition of the HIF-inhibitor FM19G11. (A) One representative experiment showing the absolute HRE-luciferase/Renilla luciferase activity ratio as the mean and SD of triplicates with and without addition of HIF inhibitor $[1 \mu \mathrm{M}]$. (B) Statistical analyses of three independent experiments as described in panel Adisplaying the normalized fraction of HRE activity after addition of the HIF inhibitor $[1 \mu \mathrm{M}]$. (C) Cell survival after exposure to tamoxifen (T) or fulvestrant (F) for six days shown as the percentage of non-drug exposed (C) cells with or without HIF inhibition with FM19G11 [1 $\mu$ M]. Statistical analyses were with Student's $t$-test, ${ }^{*} p<0.05,{ }^{* *} p<0.01,{ }^{* * *} p<0.001$. (D) Effect of increasing concentrations of FM19G11 $[0,0.3,1$, and $3 \mu \mathrm{M}]$ on cell survival in FUR2 cells that had the highest HIF2 $\alpha$ levels exposed to fulvestrant. 
(data not shown). In agreement with these data, exposure of fulvestrant-resistant cells FUR2 to increasing levels of HIF-inhibitor (FM19G11) lead to increasingly lower EGFR levels (Supplementary Figure S3B). Furthermore, stable ectopic expression of HIF $2 \alpha$ in parental MCF-7 cells led to increased levels of EGFR (Figure 6D), confirming HIF2 $\alpha$-driven induction of EGFR.

In addition to hypoxic accumulation, HIF $1 \alpha$ and HIF $2 \alpha$ can be induced in response to growth factor signaling; therefore, we tested the effect of EGFR downregulation on HIF $2 \alpha$ protein expression. siEGFR decreased HIF2 $\alpha$ protein levels under normoxia and hypoxia in antiestrogen resistant cells (Figure 6E, Supplementary Figure S6, and data not shown), suggesting that EGFR and HIF2 $\alpha$ positively regulate each others expression. Furthermore, inhibiting the activity of EGFR by Gefitinib reduced HIF2 $\alpha$ protein levels in the fulvestrant resistant cell line FUR2 (Supplementary Figure S6) especially under normoxic conditions.

\section{DISCUSSION}

The vast majority of women diagnosed with ER $\alpha$ positive breast cancer receive antiestrogen treatment. Antihormonal therapy prevent cancer regrowth and metastasis, but in about $30 \%$ of patients receiving adjuvant tamoxifen, and in almost all patients with advanced breast cancer receiving tamoxifen, the cancer becomes resistant [2].
A

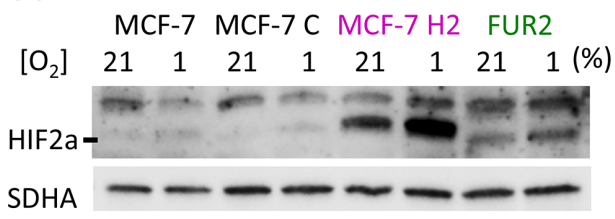

C
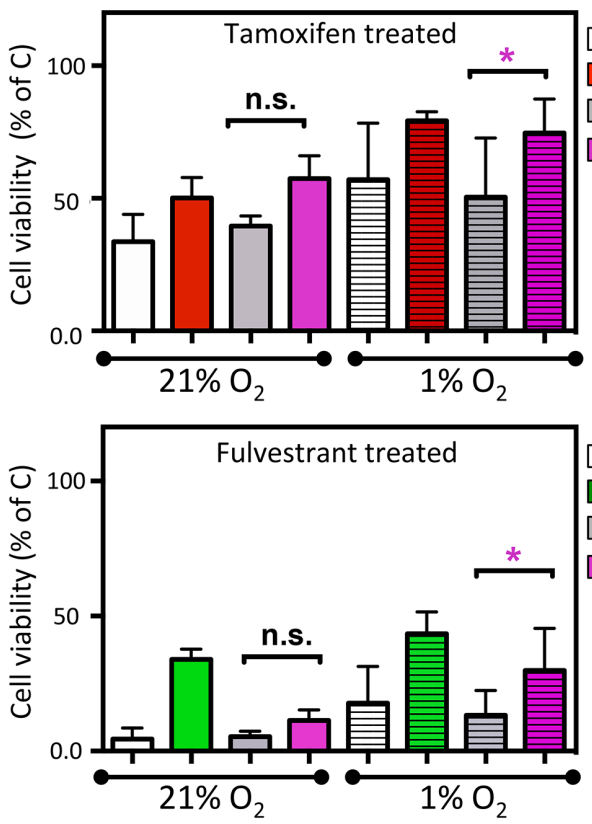

B

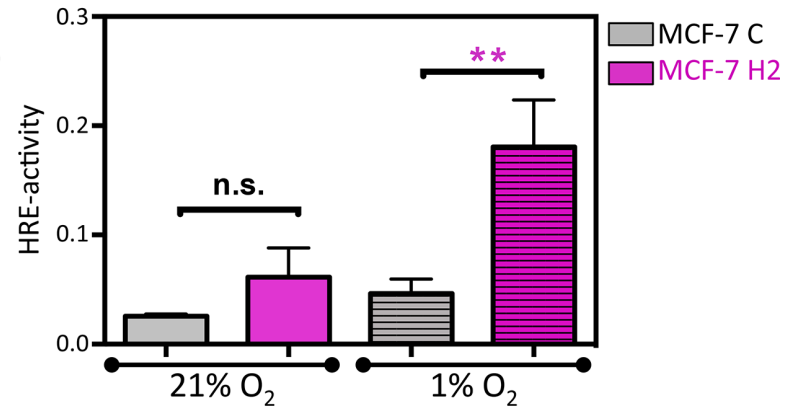

D
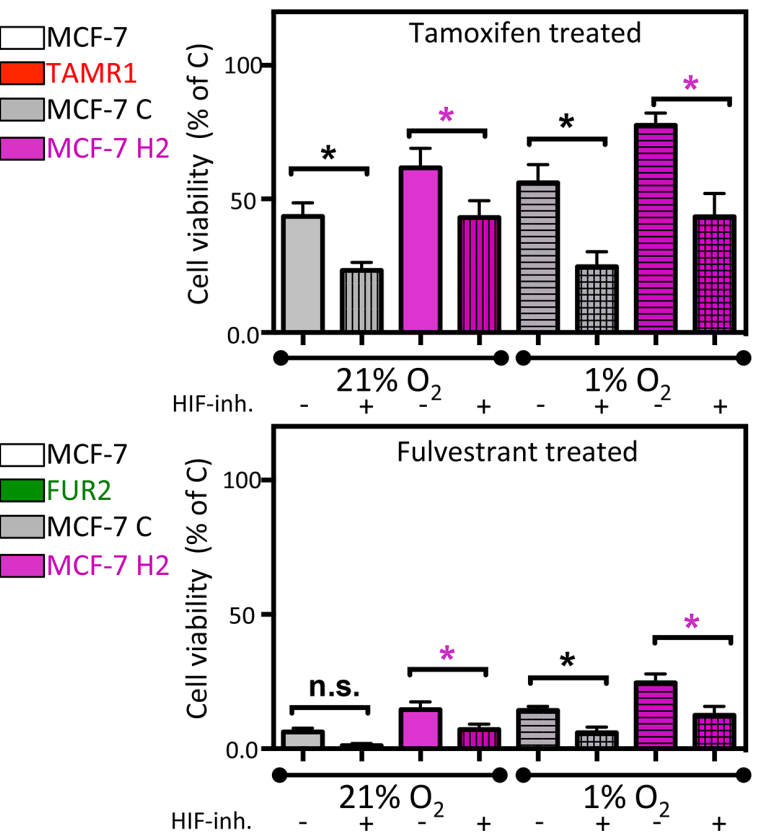

Figure 5: Effect of ectopic expression of stable HIF2 $\alpha$ in MCF-7 cells on antiestrogen sensitivity. (A) Western blot analysis of HIF $2 \alpha$ in the parental MCF-7 cells, MCF-7 cells transduced with empty vector (MCF-7C), and with the expression vector for stable HIF2 $\alpha$ (MCF-7H2) and, for comparison, FUR2 cells. (B) HIF transcriptional activity in the control (MCF-7C) and HIF2A (MCF-7H2)transduced cells under normoxic and hypoxic conditions were analyzed by HRE-luciferase reporter activity. Data presented is the mean from three independent experiments in triplicate. (C) Cell viability of MCF-7 with (MCF-7H2) and without (MCF-7C) overexpression of stable HIF $2 \alpha$ and tamoxifen or fulvestrant-resistant cells after 6-day exposure to tamoxifen (upper) or fulvestrant (lower) panel. (D) Cell viability of MCF-7 with (MCF-7H2) and without (MCF-7C) overexpression of stable HIF2 $\alpha$ and tamoxifen or fulvestrant-resistant cells after 6-day co-exposure to HIF-inhibitor FM19G11 and tamoxifen (upper) or fulvestrant (lower) panel. Three independent experiments of triplicates were performed. Statistical analysis was with Student's $t$-test. 
Currently, there is a lack of curative treatment for resistant breast cancer. Overcoming antiestrogen resistance is, therefore, a priority for breast cancer researchers, and a number of factors have been implicated in endocrine resistance including EGFR [16] and HIF-1 [12, 13, 27].

Tumor hypoxia is a well-established negative prognostic factor in cancer, including breast cancer $[13,28,29]$. Here, we show that hypoxia reduces responses to tamoxifen and fulvestrant in ER $\alpha$-positive cells: MCF-7, CAMA-1, and T47D. The low oxygen conditions induced accumulation of both HIF $1 \alpha$ and HIF $2 \alpha$, but after $24 \mathrm{~h}$ HIF $1 \alpha$ levels were declining whereas HIF $2 \alpha$ remained and effects on cell survival after antiestrogen exposure were seen after 6 days of hypoxia and drug exposure. HIF $2 \alpha$ protein and mRNA expression were increased in a panel of antiestrogen-resistant cell lines, further establishing a link between hypoxia, HIF2 $\alpha$ expression, and treatment resistance. Earlier reports showed that the cell line model of acquired antiestrogen-resistance used in this study, has clinical relevance since protein alterations reported in the resistant cell lines were found also in clinical samples from patients with antiestrogen-resistant breast cancers [30]. Our data demonstrate a direct link between HIF $2 \alpha$ and antiestrogen resistance, since ectopic expression of HIF $2 \alpha$ induced antiestrogen resistance in otherwise antiestrogensensitive breast cancer cells. Furthermore, inhibition of

A

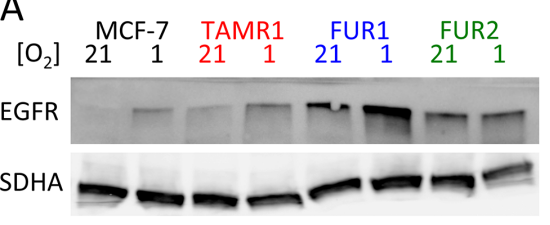

B

C
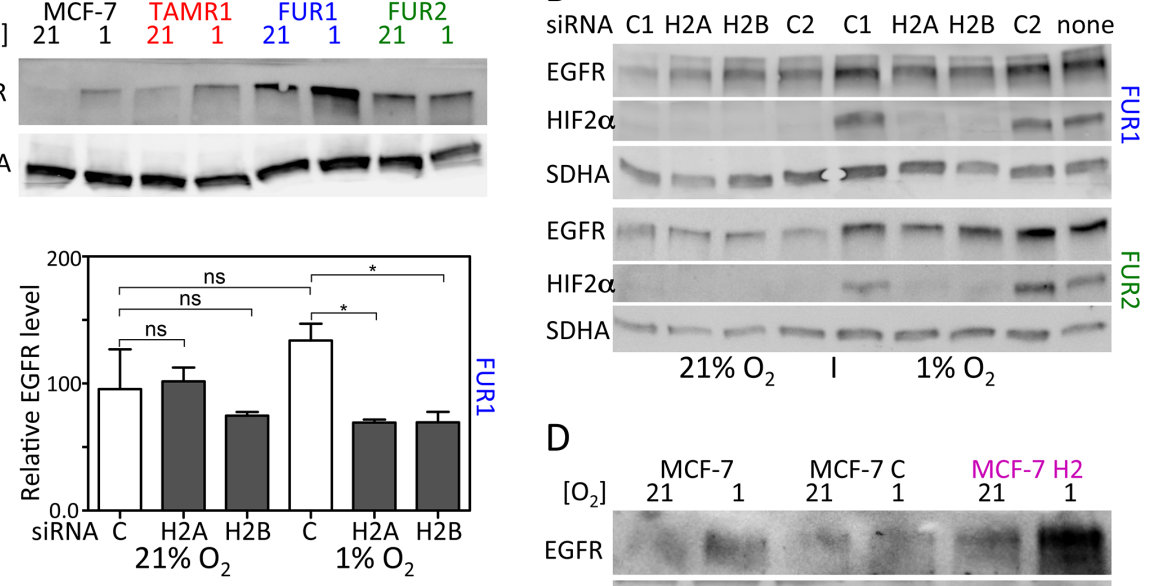

D
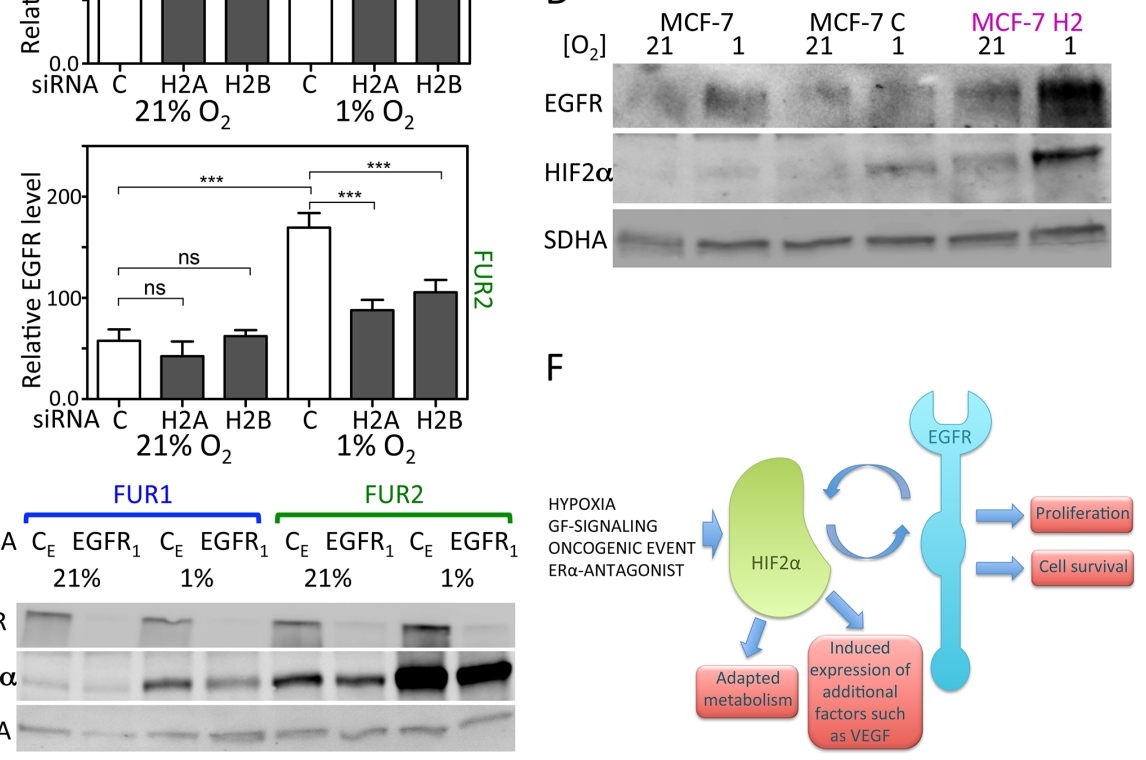

Figure 6: Effect of downregulation of HIF2 $\alpha$ on EGFR protein levels and downregulation of EGFR on HIF2 $\alpha$ protein levels in MCF-7 and antiestrogen resistant cells. (A) Protein levels of EGFR in response to $24 \mathrm{~h}$ growth under hypoxic conditions in MCF-7, TAMR1, FUR1, and FUR2 cells. SDHA was used as a loading control. One representative experiment out of three independent experiments is shown. (B) The effect of downregulation of HIF2 $\alpha$ on EGFR protein levels using two different siRNAs (H2A and H2B) was compared to the effect of two control siRNAs (C1 and C2). Samples were harvested $48 \mathrm{~h}$ after siRNA transfection and exposure to hypoxia or control conditions for $24 \mathrm{~h}$. SDHA was used as a loading control. (C) Quantification of western blots of three independent repetitions of the experiment shown in B. (D) The EGFR protein levels in response to HIF2 $\alpha$ overexpression by viral transduction (MCF-7 H2) compared to cells transduced with control vector (MCF-7 C). Loading control was SDHA. One representative experiment out of three independent experiments is shown. (E) HIF2 $\alpha$ protein levels were analyzed in response to EGFR downregulation by siRNA knockdown. One representative experiment out of three independent experiments is shown. (F) Our present data suggest that HIF2 $\alpha$ induces EGFR, which is a known contributor to resistance to antiestrogen therapy. Furthermore, we show that EGFR can induce HIF2 $\alpha$ expression. Thus, EGFR and HIF2 $\alpha$ exist with positive crosstalk to induce pro-malignant features including antiestrogen resistance. External factors such as tumor hypoxia and even therapy itself can fuel this interplay, as shown by the increased HIF2 $\alpha$ expression in antiestrogen-treated cells. 
HIF-activity by FM19G11 under conditions where HIF2 $\alpha$ is present, and HIF $1 \alpha$ levels were not detected, restored antiestrogen sensitivity in the resistant cells, TAMR1, FUR1 and FUR2. Thus, we find HIF2 $\alpha$ to be necessary and sufficient for the induction of antiestrogen resistance in the studied cells. Our findings highlight the potential feasibility of targeting HIF2 $\alpha$ to overcome antiestrogen resistance. A similar situation is seen in clear cell renal carcinoma, where the negative regulator of HIF $1 \alpha$ and HIF $2 \alpha$ is frequently lost, and HIF $2 \alpha$ is an oncoprotein and HIF $1 \alpha$ acts as a tumor suppressor [31]. The transcriptional activity of HIF $2 \alpha$ is less strictly regulated by oxygen conditions since factor inhibiting HIF1 (FIH1) has less affinity for HIF $2 \alpha$ [32] allowing it to be active at physiological oxygen levels if accumulated as seen in the MCF-7 derived antiestrogen-resistant cell lines here.

Our data suggest that one mechanism whereby HIF $2 \alpha$ contributes to the antiestrogen resistance is by increasing the protein levels of EGFR (Figure 6E), which has been shown to play an important role for fulvestrant resistance in cell lines [16] and is inversely linked to antiestrogen-response in clinical samples [11]. EGFR knockdown and inhibition, in turn, demonstrated that EGF-signaling contributes to the high HIF2 $\alpha$ levels in the resistant cells (Figure 6 and Supplementary Figure 6). Based on these data, we hypothesize that the collective activities of EGFR and HIF2 $\alpha$ lead to therapeutic resistance and potentially other pro-malignant traits such as angiogenesis, proliferation and altered metabolism (Figure 6F). Our data suggest that this "vicious circle" is fueled by hypoxia and even antiestrogen-therapy itself, since tamoxifen, fulvestrant, and ER $\alpha$ downregulation increase HIF2 $\alpha$ expression (Figure 2 and 3, and Supplementary Figure S2). Our present data are in line with the earlier publication by Franovic et al showing that HIF2 $\alpha$ confers growth factor-independent proliferation to numerous cancers, including breast cancer, regardless of their tissue of origin or mutational status and that the proliferative effect was exerted via receptor tyrosine kinases, including EGFR [33].

The general view is that HIF $1 \alpha$ and HIF $2 \alpha$ are mainly regulated post-translationally by oxygen-dependent proteasomal degradation [34, 35]. However, growth factor signaling has been shown to regulate HIF $1 \alpha$ at both the transcriptional and translational level [36-41], and HIF2 $\alpha$ transcription in hypoxic neuroblastoma cells is regulated by IGF-2 [23, 42]. Here, we show that EGFR knockdown downregulates the high HIF $2 \alpha$ levels in antiestrogenresistant cells (Figure 6E and 6F).

Tamoxifen-resistant cell growth has previously been shown to depend on ER $\alpha$ [30] and recently to be due to crosstalk with the Aurora kinase A [43], which is a determinant of tamoxifen sensitivity through phosphorylation of ER $\alpha$ [44]. Despite that we find ER $\alpha$ protein expression being downregulated by hypoxia, a phenomenon that can be linked to HIF1 $\alpha$ [45], ER $\alpha$ signaling persisted under hypoxic conditions (Figure 1C). HIF $1 \alpha$ has been reported to promote ligand-independent ER $\alpha$ signaling, presumably, by direct binding of HIF $1 \alpha$ to ER $\alpha$ [46]. Given the high homology between HIF $1 \alpha$ and HIF $2 \alpha$, HIF $2 \alpha$ may also be able to propagate ER $\alpha$ signaling; this requires experimental validation.

As mentioned above, tamoxifen-resistant cells, including TAMR1, depend on ER $\alpha$-activity also in the presence of tamoxifen [30, 43]. The situation is quite different in fulvestrant treatment and fulvestrant-resistant cells where ER $\alpha$ is lost because of the destabilizing effect of fulvestrant-binding and the resistant cells take advantage of ER $\alpha$ independent mechanisms including activation of HER/EGFR pathways [16]. A similar setting to fulvestrant treatment is the exposure to siER $\alpha$ (Supplementary Figure 2) where we see increased HIF $2 \alpha$ levels. The fact that HIF $2 \alpha$ infers resistance to both tamoxifen and fulvestrant and that HIF-inhibition/ downregulation increases sensitivity to both tamoxifen and fulvestrant indicates that HIF2 $\alpha$ confers increased antiestrogen resistance in a general manner.

The frequent presence of tumor hypoxia, HIF $1 \alpha$, and HIF $2 \alpha$ in solid tumors, including breast cancer, suggests that these tumor areas may possess inherent antiestrogen resistance that can withstand therapy and contribute to treatment failure. It now appears that antiestrogen treatment itself might exacerbate the resistance phenotype. Our finding that HIF inhibition by FM19G11 restores antiestrogen sensitivity indicates that targeting HIF activity may be a feasible strategy to counteract antiestrogen resistance in clinical practice. However, this requires further investigation in the clinical setting.

\section{MATERIALS AND METHODS}

\section{Cells and cell culture}

The ER $\alpha$-positive human breast cancer cells MCF-7, CAMA-1, and T47D were obtained from the American Type Culture Collection (ATCC, USA). The MCF-7/S0.5 subline (MCF-7, parental cells) and the antiestrogen resistant strains that were derived from this cell line, MCF-7/TAM ${ }^{\mathrm{R}}-1$ (TAMR1), MCF-7/182 ${ }^{\mathrm{R}}-6$ (FUR1) and MCF-7/164 -7 (FUR2) were obtained from Anne Lykkesfeldt, Danish Cancer Society Research Center. The MCF-7 sub-line was established by stepwise reduction of the serum concentration from $5 \%$ to $0.5 \%$ [17]. The tamoxifen-resistant TAMR-1 cell line and the fulvestrant-resistant cell lines FUR1 and FUR2 were established by long term selection with $1 \mu \mathrm{M}$ tamoxifen, $0.1 \mu \mathrm{M}$ ICI 182,780 (fulvestrant) and $0.1 \mu \mathrm{M}$ ICI 164,384, respectively, as previously described $[18,19]$. Due to the long periods of culture, MCF-7 cell line authenticity was tested and positively confirmed (DSMZ, Germany). All cells were grown in standard DMEM/F12 medium (Thermo Fisher Scientific, MA) with FCS (MCF-7, 
TAMR1, FUR1, and FUR2: 1\%; T47D and CAMA-1: $10 \%$, Biosera, MO), penicillin and streptomycin (100 units/ml, Hyclone, GE Healthcare, UT) and insulin (100 units/ml, Actrapid, Novo Nordisk, Denmark). The cells were routinely cultured at $37^{\circ} \mathrm{C}, 5 \% \mathrm{CO}_{2}$, and air oxygen levels, kept at low passage numbers, and checked for Mycoplasma on a monthly basis (results were consistently negative). Antiestrogen-resistant cells were maintained in their respective antiestrogen until 1-2 weeks prior to experimental use. Growth medium with additives was changed every third day. Hypoxic cell culture experiments were performed in a Don Whitley Hypoxystation (Don Whitley Scientific, Shipley, UK) under identical culture conditions except for oxygen. Cells were treated with tamoxifen (4-hydroxytamoxifen; Sigma Aldrich, MO; $0.5 \mu \mathrm{M}$ ) or fulvestrant (ICI 182.780; Tocris Bioscience, UK; $0.5 \mu \mathrm{M}$ ) as indicated.

\section{Immunoblotting}

Whole cell lysates (40-80 $\mu \mathrm{g}$ protein in RIPA buffer with Complete, Roche, Switzerland) were electrophoretically separated (7.5\% Mini TGX gel, BioRad Laboratories CA). Protein detection was performed using anti-HIF1 $\alpha$ (Becton Dickinson, NJ), anti-HIF1 $\beta$ (Ab126985) anti-HIF2 $\alpha$ (Ab199, Abcam, UK), anti-EGFR (DAK-H1-WT, Dako, Denmark), ER $\alpha$ (Cell Signaling Technologies, MA), actin (MP Biomedicals, CA) and SDHA (Ab14715, Abcam).

\section{RNA isolation, cDNA synthesis, and qRT-PCR}

cDNA was generated from purified RNA (QIAshredder, RNeasy, Qiagen, Netherlands, Applied Biosystems). Genomic DNA was removed by RNasefree DNase (Promega, WI). qRT-PCR was performed (7300 RT-PCR, Applied Biosystems) with SYBR Green (Applied Biosystems) using forward and reverse primers for: HIF $1 \alpha$ (f-5'TTCCAGTTACGTTCCTTCGATCA3', r-5'TTTGAGGACT-TGCGCTTTCA3'), HIF2 $\alpha$ (f-5'GC TCTCCACGGCCTGATA3', r-5'TTGTCACAC-CTATGG CATATCACC3') and EGFR (f-5'CTAATTTGGTGGCTG CCTTTCT3', r-5'CCCGAGTATCTCAACACTGTCC3'). Gene expression was normalized using the geometric mean of three reference genes: SDHA (f- 5'TGGGAACA AGAGGGCATC-TG3', r 5'CCACCACTGCATCAAATT CATG3'), UBC (f-5'ATTTGGGTCGCGGTT-CTTG3', r 5'TGCCTTGACATTCTCGATGGT3'), and YWHAZ (f-5'ACTTTTGGTACA-TTGTGTGGCTTCAA3', r- 5'CC GCCAGGACAAACCAGTAT3').

\section{Cell counting}

Cells were exposed to the specified conditions six days prior to detachment, trypan blue staining, and counting in an automated cell counter according to the manufacturer's protocol (Countess, Life Technologies).

\section{WST-1 assay}

Cells were treated with the specified conditions in 96-well plates for up to nine days. Relative viable cell numbers were measured by WST-1 (Roche) at normoxia after change to normoxic growth medium to minimize the risk that hypoxia would interfere with the detection of metabolically active cells. Optical densities were measured at 450 and $630 \mathrm{~nm}$ (Synergy 2, BioTek, VT).

\section{Luciferase assays}

Cells were transfected with HRE-luc or ERE-luc reporter constructs (HRE, Addgene, MA, \#26731 deposited by N Chandel; ERE; pGL2 luciferase reporter plasmid with ER $\alpha$-responsive element) and pRL-SV40 (internal control). For ERE-luc analyses, cells were kept in standard growth medium supplemented with $10 \mathrm{nM}$ estrogen, $1 \mu \mathrm{M}$ tamoxifen, or both and cultured $72 \mathrm{~h}$ in $21 \%$ or $1 \%$ oxygen. Cell lysates were analyzed using Dual-Luciferase Reporter Assay (Promega) and normalized to internal controls.

\section{HIF inhibitor}

FM19G11 (Calbiochem, Merck Millipore, MA) $[25,47]$ was diluted in DMSO and used at final concentrations of $0.5-3.0 \mu \mathrm{M}$. The corresponding amount of DMSO was added to controls.

\section{Ectopic expression of HIF2A and gene silencing}

Parental MCF-7 cells was transduced with the retroviral vector encoding a stable version of HIF2 $\alpha$ HA-HIF $2 \alpha$ P531A-pBabe-puro (Addgene; Dr. W.G. Kaelin) [26] or empty pBabe-puro. Transduced cells were selected by puromycin. HIF $2 \alpha$ silencing was performed using two custom made siRNAs targeting different HIF2 $\alpha$ mRNA regions and two control siRNAs (Life Technologies). EGFR silencing was performed using validated silencer siEGFR (s563 and s564) and controls (Life Technologies). ER $\alpha$ silencing was performed using pre-designed siRNAs (s4823 and s4825) and controls (Life Technologies).

\section{Statistical analyses}

Statistical analyses were conducted in GraphPad Prism 6.0 (GraphPad Software, CA). Student's $t$-test was performed and results are shown as mean $+/-1$ SD with $p$-values: ${ }^{*} p<0.05, * * p<0.01, * * * p<0.001$.

\section{ACKNOWLEDGMENTS}

The authors thank Ms Sofia E Svensson and $\mathrm{Mr}$ Mats Jonsson for technical assistance. 


\section{FUNDING}

The Swedish Research Council, Crafoord Foundation, Swedish Cancer Research Campaign, Hans von Kantzow's Research Foundation, Percy Falk's Foundation, the Royal Physiographic Society Lund, and Gunnar Nilsson's Foundation. The funders had no role in study design, data collection and analysis, decision to publish, or preparation of the manuscript.

\section{CONFLICTS OF INTEREST}

The authors declare no conflicts of interest.

\section{REFERENCES}

1. Musgrove A, Sutherland RL. Biological determinants of endocrine resistance in breast cancer. Nature Reviews Cancer. 2009; 9:631-643.

2. Ring A, Dowsett M. Mechanisms of tamoxifen resistance. Endocr Relat Cancer. 2004; 11:643-658.

3. Tzukerman MT, Esty A, Santiso-Mere D, Danielian P, Parker MG, Stein RB, Pike JW, McDonnell DP. Human estrogen receptor transactivational capacity is determined by both cellular and promoter context and mediated by two functionally distinct intramolecular regions. Mol Endocrinol. 1994; 8:21-30.

4. Jones SE. Fulvestrant: an estrogen receptor antagonist that downregulates the estrogen receptor. Semin Oncol. 2003; 30:14-20.

5. Brahimi-Horn MC, Chiche J, Pouyssegur J. Hypoxia and cancer. J Mol Med. 2007; 85:1301-1307.

6. Harris AL. Hypoxia - a key regulatory factor in tumour growth. Nature Rev Cancer. 2002; 2:38-47.

7. White FC, Carroll SM, Kamps MP. VEGF mRNA is reversibly stabilized by hypoxia and persistently stabilized in VEGF-overexpressing human tumor cell lines. Growth Factors. 1995; 12:289-301.

8. Jögi A. Tumour hypoxia and the hypoxia-inducible transcription factors: Key players in cancer progression and metastasis. In: Mazurek S, Shoshan MC, eds. Tumor Cell Metabolism. (Wien: Springer-Verlag) (2014).

9. Helczynska K, Larsson AM, Holmquist Mengelbier L, Bridges E, Fredlund E, Borgquist S, Landberg G, Påhlman S, Jirström K. Hypoxia-inducible factor-2alpha correlates to distant recurrence and poor outcome in invasive breast cancer. Cancer Res. 2008; 68:9212-9220.

10. Slamon DJ, Clark GM, Wong SG, Levin WJ, Ullrich A, McGuire WL. Human breast cancer: correlation of relapse and survival with amplification of the HER-2/neu oncogene. Science. 1987; 235:177-182.

11. Nicholson RI, McClelland RA, Gee JM, Manning DL, Cannon P, Robertson JF, Ellis IO, Blamey RW. Epidermal growth factor receptor expression in breast cancer: association with response to endocrine therapy. Breast Cancer Res Treat. 1994; 29:117-125.

12. Jia X, Hong Q, Lei L, Li D, Li J, Mo M, Wang Y, Shao Z, Shen Z, Cheng J, Liu G. Basal and therapy-driven hypoxiainducible factor-1alpha confers resistance to endocrine therapy in estrogen receptor-positive breast. Oncotarget. 2015; 6:8648-8662. doi: 10.18632/oncotarget.1697.

13. Samantha D, Gilkes DM, Chaturvedi P, Xiang L, Semenza GL. Hypoxia-inducible factors are required for chemotherapy resistance of breast cancer stem cells. Proc Natl Acad Sci U S A. 2015; 50:E5429-5438.

14. Uniacke J, Holterman CE, Lachance G, Franovic A, Jacob MD, Fabian MR, Payette J, Holcik M, Pause A, Lee S. An oxygen-regulated switch in the protein synthesis machinery. Nature. 2012; 486:126-129.

15. Franovic A, Gunaratnam L, Smith K, Robert I, Patten D, Lee S. Translational up-regulation of the EGFR by tumor hypoxia provides a nonmutational explanation for its overexpression in human cancer. Proc Natl Acad Sci U S A. 2007; 104:13092-13097.

16. Frogne T, Benjaminsen RV, Sonne-Hansen K, Sorensen BS, Nexo E, Laenkholm AV, Rasmussen LM, Riese DJ, 2nd, de Cremoux P, Stenvang J, Lykkesfeldt AE. Activation of ErbB3, EGFR and Erk is essential for growth of human breast cancer cell lines with acquired resistance to fulvestrant. Breast Cancer Res Treat. 2009; 114:263-275.

17. Briand P, Lykkesfeldt AE. Effect of estrogen and antiestrogen on the human breast cancer cell line MCF-7 adapted to growth at low serum concentration. Cancer Res. 1984; 44:1114-1119.

18. Lykkesfeldt AE, Larsen SS, Briand P. Human breast cancer cell lines resistant to pure anti-estrogens are sensitive to tamoxifen treatment. Int J Cancer. 1995; 61:529-534.

19. Lykkesfeldt AE, Madsen MW, Briand P. Altered expression of estrogen-regulated genes in a tamoxifen-resistant and ICI 164,384 and ICI 182,780 sensitive human breast cancer cell line, MCF-7/TAMR-1. Cancer Res. 1994; 54:1587-1595.

20. Jordan VC. The new biology of estrogen-induced apoptosis applied to treat and prevent breast cancer. Endocr Relat Cancer. 2015; 22:R1-31.

21. Lønning PE, Taylor PD, Anker G, Iddon J, Wie L, Jørgensen LM, Mella O, Howell A. High-dose estrogen treatment in postmenopausal breast cancer patients heavily exposed to endocrine therapy. Breast Cancer Res Treat. 2001; 67:111-116.

22. Shim WS, Conaway M, Masamura S, Yue W, Wang JP, Kmar R, Santen RJ. Estradiol hypersensitivity and mitogenactivated protein kinase expression in long-term estrogen deprived human breast cancer cells in vivo. Endocrinology. 2000; 141:396-405.

23. Jögi A, Øra I, Nilsson H, Lindeheim A, Makino Y, Poellinger L, Axelson H, Påhlman S. Hypoxia alters 
gene expression in human neuroblastoma cells toward an immature and neural crest-like phenotype. Proc Natl Acad Sci U S A. 2002; 99:7021-7026.

24. Elias D, Vever H, Laenkholm AV, Gjerstorff MF, Yde CW, Lykkesfeldt AE, Ditzel HJ. Gene expression profiling identifies FYN as an important molecule in tamoxifen resistance and a predictor of early recurrence in patients treated with endocrine therapy. Oncogene. 2015; 34:1919-1927.

25. Moreno-Manzano V, Rodriguez-Jimenez FJ, Acena-Bonilla JL, Fustero-Lardies S, Erceg S, Dopazo J, Montaner D, Stojkovic M, Sanchez-Puelles JM. FM19G11, a new hypoxia-inducible factor (HIF) modulator, affects stem cell differentiation status. J Biol Chem. 2010; 285:1333-1342.

26. Kondo K, Kico J, Nakamura E, Lechpammer M, Kaelin WG. Inhibition of HIF is necessary for tumor suppression by the von Hippel-Lindau protein. Cancer Cell. 2002; 1:237-246.

27. Yang J, AlTahan A, Jones DT, Buffa FM, Bridges E, Interiano RB, Qu C, Vogt N, Li JL, Baban D, Ragoussis J, Nicholson R, et al. Estrogen receptor-alpha directly regulates the hypoxia-inducible factor 1 pathway associated with antiestrogen response in breast cancer. Proc Natl Acad Sci U S A. 2015; 112:15172-15177.

28. Milani M, Harris AL. Targeting tumour hypoxia in breast cancer. Eur J Cancer. 2008; 44:2766-2773.

29. Vaupel P, Briest S, Hockel M. Hypoxia in breast cancer: pathogenesis, characterization and biological/therapeutic implications. Wien Med Wochenschr. 2002; 152:334-342.

30. Thrane S, Lykkesfeldt AE, Larsen M, Sørensen B, Yde CW. Estrogen receptor alpha is the major driving factor for growth in Tamoxifen resistance breast cancer and supported by HER/ ERK signaling. Breast Cancer Res Treat. 2013; 139:71-80.

31. Shen C, Kaelin WG, Jr. The VHL/HIF axis in clear cell renal carcinoma. Semin Cancer Biol. 2013; 23:18-25.

32. Bracken CP, Fedele AO, Linke S, Balrak W, Lisy K, Whitelaw ML, Peet DJ. Cell-specific regulation of hypoxiainducible factor (HIF)-1alpha and HIF-2alpha stabilization and transactivation in a graded oxygen environment. J Biol Chem. 2006; 281:22575-22585.

33. Franovic A, Holterman CE, Payette J, Lee S. Human cancers converge at the HIF-2alpha oncogenic axis. Proc Natl Acad Sci U S A. 2009; 106:21306-21311.

34. Epstein AC, Gleadle JM, McNeill LA, Hewitson KS, O'Rourke J, Mole DR, Mukherji M, Metzen E, Wilson MI, Dhanda A, Tian YM, Masson N, et al. C. elegans EGL-9 and mammalian homologs define a family of dioxygenases that regulate HIF by prolyl hydroxylation. Cell. 2001; 107:43-54.

35. Jaakkola P, MoleDR, Tian YM, Wilson MI, Gielbert J, Gaskell SJ, Kriegsheim A, Hebestreit HF, Mukherji M, Schofield CJ, Maxwell PH, Pugh CW, et al. Targeting of HIF-a to the von Hippel-Lindau ubiquitylation complex by o2-regulated prolyl hydroxylation. Science. 2001; 292:468-472.

36. Feldser D, Agani F, Iyer NV, Pak B, Ferreira G, Semenza G. Reciprocal positive regulation of hypoxia-inducible factor 1alpha and insulin-like growth factor 2. Cancer Res. 1999; 59:3915-3918.

37. Zhong H, Chiles K, Feldser D, Laughner E, Hanrahan C, Georgescu MM, Simons JW, Semenza GL. Modulation of HIF-1a expression by the epidermal growth factor/ phosphatidylinositol 3-kinase/PTEN/AKT/FRAP pathway in human prostate cancer cells: implications for tumor angiogenesis and therapeutics. Cancer Res. 2000; 60: 1541-1545.

38. Semenza GL. Oxygen sensing, homeostasis, and disease. N Engl J Med. 2011; 365:537-547.

39. Laughner E, Taghavi P, Chiles K, Mahon PC, Semenza GL. HER2 (neu) signaling increases the rate of hypoxiainducible factor 1alpha (HIF-1alpha) synthesis: novel mechanism for HIF-1-mediated vascular endothelial growth factor expression. Mol Cell Biol. 2001; 21:3995-4004.

40. Treins C, Giorgetti-Peraldi S, Murdaca J, Semenza GL, Van Obberghen E. Insulin stimulates hypoxia-inducible factor 1 through a phosphatidylinositol 3-kinase/target of rapamycin-dependent signaling pathway. J Biol Chem. 2002; 277:27975-27981.

41. Beppu K, Nakamura K, Linehan WM, Rapisarda A, Thiele CJ. Topotecan blocks hypoxia-inducible factor-1alpha and vascular endothelial growth factor expression induced by insulin-like growth factor-I in neuroblastoma cells. Cancer Res. 2005; 65:4775-4781.

42. Mohlin S, Hamidian A, Pahlman S. HIF2A and IGF2 expression correlates in human neuroblastoma cells and normal immature sympathetic neuroblasts. Neoplasia. 2013; 15:328-334.

43. Thrane S, Pedersen AM, Thomsen MB, Kirkegaard T, Rasmussen BB, Duun-Henriksen AK, Laenkholm AV, Bak M, Lykkesfeldt AE, Yde CW. A kinase inhibitor screen identifies Mcl-1 and Aurora kinase A as novel treatment targets in antiestrogen-resistant breast cancer cells. Oncogene. 2014; 32:4199-4210.

44. Zheng XQ, Guo JP, Yang H, Kanai M, He LL, Li YY, Koomen JM, Minton S, Gao M, Ren XB, Coppola D, Cheng JQ. Aurora-A is a determinant of tamoxifen sensitivity through phosphorylation of ERalpha in breast cancer. Oncogene. 2014; 33:4985-4996.

45. Ryu K, Park C, Lee Y. Hypoxia-inducible factor 1 alpha represses the transcription of the estrogen receptor alpha gene in human breast cancer cells. Biochem Biophys Res Commun. 2011; 407:831-836.

46. Cho J, Bahn JJ, Park M, Ahn W, Lee YJ. Hypoxic activation of unoccupied estrogen-receptor-alpha is mediated by hypoxia-inducible factor-1 alpha. J Steroid Biochem Mol Biol. 2006; 100:18-23.

47. Rodriguez-Jimenez FJ, Moreno-Manzano V, MateosGregorio P, Royo I, Erceg S, Murguia JR, Sanchez-Puelles JM. FM19G11: A new modulator of HIF that links mTOR activation with the DNA damage checkpoint pathways. Cell Cycle. 2010; 9:2803-2813. 